\title{
A 60 años de la clorpromazina.
}

\author{
Sixty years after chlorpromazine.
}

Lizardo Cruzado ${ }^{1}$

Si hemos de creer cum grano salis a Trevor Turner, antes de la introducción de la clorpromazina los congresos médicos de la especialidad psiquiátrica solían ostentar entre sus tópicos estelares a la actualización sobre correas y camisolas de fuerza para contener a los pacientes psicóticos y agitados, pues dichos heroicos remedios eran imprescindibles a falta de otros recursos terapéuticos (1).

Así como esta anécdota despierta irrisión, hoy no nos suscitan mayor curiosidad los fármacos antihistamínicos, a los que asumimos cual triviales productos de venta libre para las alergias. Es difícil imaginar que en su momento estos fármacos constituyeron un hallazgo clave de la farmacología y es imposible recapturar el ambiente de excitación y entusiasmo que ellos generaron en las décadas de 1940 y 1950 (al punto que más de un Premio Nobel fue destinado a los científicos investigadores de la fisiología histaminérgica). Sin embargo, la clorpromazina surgió precisamente de entre un numeroso grupo de moléculas con propiedades bloqueantes de la histamina (2).

Pero quizá más arduo sea imaginar siquiera el panorama de los asilos de enfermos mentales en las épocas de Kraepelin y Bleuler, cuando según narra un escriba: "se podían ver animales mejor tratados y mejor alojados en el zoológico que los pacientes hospitalizados en muchas instituciones psiquiátricas" (3). Y el número de ellos era tan vasto que buena parte de la labor de los escasos psiquiatras debía consumirse en administrar la abrumadora logística de roperías y vituallas -téngase en cuenta que a fines de la década de 1940 más de la mitad de las camas hospitalarias disponibles eran destinadas a pacientes psiquiátricos- (2).

Hasta antes de 1950 los medicamentos usualmente empleados en el campo psiquiátrico adormecían al paciente de manera temporal sin alterar la psicopatología de sus respectivos males. La eficacia de estos fármacos era equiparable a la de la silla giratoria o las duchas de agua helada: sólo aturdían a los individuos en los paroxismos de su locura sin moverles un ápice de su desquiciamiento. Había asomado ya la terapia convulsiva, cierto, pero con numerosas complicaciones y restricciones. De hecho, para el zeitgeist mayoritariamente psicoanalítico de la época era casi una locura pensar que una molécula pudiese actuar en el cerebro como tratamiento de la esquizofrenia. Así, la clorpromazina ingresó en su momento al enorme mercado norteamericano cautelosamente rotulada nada menos que como "antiemético".

La apasionante historia que exalta los nombres de Delay, Deniker, Laborit y Charpentier, es bien conocida; asimismo los avatares de las moléculas precursoras de la clorpromazina, sintetizadas varias décadas antes y ensayadas con propósitos tan disímiles que, con acierto, se ha definido a la introducción en terapéutica de la clorpromazina como "la historia de un medicamento en busca de enfermedad". Casi anónimo es, en cambio, un tal Jacques Lh., varón de 24 años aquejado de manía, el primer paciente que fue medicado con la clorpromazina y cuyo nombre traemos a colación ante la imposibilidad de mencionar a los millones de personas beneficiadas con el nuevo fármaco. Valga citar que para 1957, a sólo cinco años de su aparición, el consumo de clorpromazina jen kilogramos administrados! se había incrementado en más de $500000 \%$ y en su primera década cincuenta millones de personas alrededor del globo habían llegado a recibirla (2).

1 Psiquiatra, Facultad de Medicina Alberto Hurtado, Universidad Peruana Cayetano Heredia. Instituto Nacional de Salud Mental Honorio Delgado - Hideyo Noguchi. Lima, Perú. 
La clorpromazina surgió en una época cuando no existían aún ensayos clínicos, pero sus inusitados efectos clínicos hicieron patente la necesidad de nuevos paradigmas para evaluar la eficacia y seguridad de los emergentes psicofármacos, lo que impuso una estructura distinta a la investigación biomédica; con la clorpromazina se inauguraron además fructuosos derroteros para la indagación de los mecanismos neurobiológicos subyacentes a la patología mental, hasta hoy detentadores de valor heurístico. Y si en su respectiva circunstancia la psiquiatría hubo apelado a recursos que hoy, contemplándolos desde una perspectiva de anacronismo, nos mueven a escándalo (los abscesos de fijación, verbigracia, o las lobotomías), es también a partir de la clorpromazina que la psiquiatría empezó a incorporar en su praxis una reflexión bioética imprescindible y progresivamente creciente (4).

Una somera hojeada por las revistas científicas de la época, aún sin detenerse en la bibliografía académica propiamente dicha sino simplemente en el profuso avisaje, nos proporcionará una noción del entusiasmo concitado por la novedosa molécula de la clorpromazina: anuncios que proclamaban su efectividad ante molestias de la menopausia, la ansiedad, desórdenes gastrointestinales diversos, la psoriasis, bursitis, artritis, asma, hiperactividad y trastornos infantiles de conducta, alcoholismo, como medicación prequirúrgica y en el ubicuo "estrés" emocional, dan cuenta de su auge. Se atribuye al reputado psicofarmacólogo Heinz Lehmann el dicterio de que podría tratarse toda la patología psiquiátrica con solamente dos moléculas: un estimulante anfetamínico y una molécula depresora, la clorpromazina. Sesenta años después, y con tantos compuestos originales derivados de la estructura básica de tres ciclos de carbono propia de la clorpromazina, cabe repensar la frase de Lehmann contemplando la pléyade de me-too-drugs de hoy que no necesariamente son un aporte real a la psicofarmacopea sino una alevosa oportunidad para los ominosos conflictos de interés de la psiquiatría con la industria farmacéutica.

Proponiendo una alegoría abarcativa a lo largo del tiempo que grafique la histórica epopeya del primer antipsicótico, podría parangonarse a Jean Delay, propulsor prístino de la clorpromazina, con Philippe Pinel, también médico, también galo y también liberador de pacientes encadenados: a nuestra vieja molécula se le han descubierto ahora propiedades antivíricas y hasta jantipriónicas! (5) pero no podemos soslayar que su rol ha rebasado la trascendencia terapéutica para apuntalar una tradición profesional venerable pero aún con asignaturas pendientes en su perspectiva: si bien las personas pueden ser liberadas de las fuerzas biológicas internas que contribuyen al sufrimiento de la enfermedad mental y allí a la clorpromazina y fármacos sucesores les corresponde rol fundamental, la psiquiatría debe legítimamente revigorizar su proyecto de liberación de todas las otras fuerzas opresoras de índole social, política y cultural sobre la salud mental (6).

\section{REFERENCIAS BIBLIOGRÁFICAS}

1. Turner T. Chlorpromazine: unlocking psychosis. BMJ 2007; 334 (Suppl. 1): s7.

2. Shorter E. A history of psychiatry. New York: John Wiley \& Sons; 1997.

3. Healy D. The creation of psychopharmacology. Massachussetts: Harvard University Press; 2002.
4. Pignarre P. El gran secreto de la industria farmacéutica. Barcelona: Gedisa; 2005.

5. Medrano J. Las bodas de diamante de la clorpromazina. Rev Asoc Esp Neuropsiq. 2012; 32 (116): 851-866.

6. Cohen CI, Timimi S (eds.) Liberatory Psychiatry: Philosophy, Politics and Mental Health. New York: Cambridge University Press; 2008. 